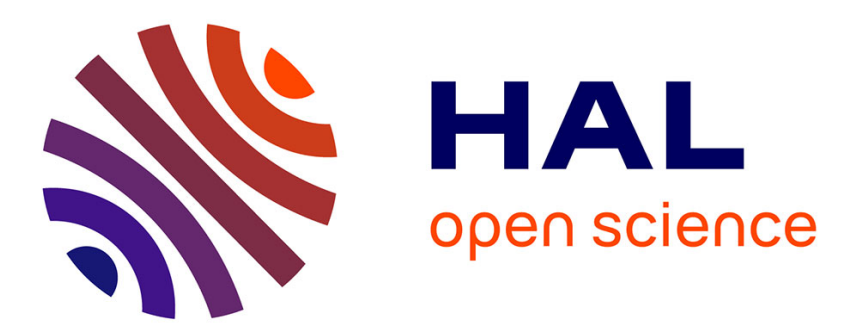

\title{
Anticompetitive Vertical Merger Waves
}

Johan Hombert, Jérôme Pouyet, Nicolas Schutz

\section{To cite this version:}

Johan Hombert, Jérôme Pouyet, Nicolas Schutz. Anticompetitive Vertical Merger Waves. Journal of Industrial Economics, 2020, 67 (3-4), pp.484-514. 10.1111/joie.12204 . hal-03330587

\section{HAL Id: hal-03330587 https://hal.science/hal-03330587}

Submitted on 1 Sep 2021

HAL is a multi-disciplinary open access archive for the deposit and dissemination of scientific research documents, whether they are published or not. The documents may come from teaching and research institutions in France or abroad, or from public or private research centers.
L'archive ouverte pluridisciplinaire HAL, est destinée au dépôt et à la diffusion de documents scientifiques de niveau recherche, publiés ou non, émanant des établissements d'enseignement et de recherche français ou étrangers, des laboratoires publics ou privés. 


\title{
ANTICOMPETITIVE VERTICAL MERGER WAVES*
}

\author{
JOHAN HOMBERT ${ }^{\dagger}$ \\ JÉRÔME POUYET PE $^{\ddagger}$ \\ NiCOLAS SCHUTZ
}

\begin{abstract}
We develop a model of vertical merger waves and use it to study the optimal merger policy. As a merger wave can result in partial foreclosure, it can be optimal to ban a vertical merger that eliminates the last unintegrated upstream firm. Such a merger is more likely to worsen market performance when the number of downstream firms is large relative to the number of upstream firms, and when upstream contracts are non-discriminatory, linear, and public. On the other hand, the optimal merger policy can be non-monotonic in the strength of synergies or in the degree of downstream product differentiation.
\end{abstract}

${ }^{*}$ We thank the editor, two anonymous referees, Marie-Laure Allain, Helmut Bester, Bernard Caillaud, Yeon-Koo Che, Yongmin Chen, Liliane Giardino-Karlinger, Dominik Grafenhofer, Michael Katz, Sebastian Kranz, Tim Lee, Volker Nocke, Jean-Pierre Ponssard, Patrick Rey, Michael Riordan, Bernard Salanié, Helen Weeds and numerous seminar and conference participants for helpful comments. We gratefully acknowledge financial support from CEPREMAP and the German Science Foundation (CRC TR 15 and CRC TR 224).

†Authors' affiliations: HEC Paris, 1 rue de la Libération, 78351, Jouy-en-Josas, France. Also affiliated with CEPR.

e-mail: hombert@hec.fr.

‡THEMA-CNRS, ESSEC Business School, Université de Cergy-Pontoise, 3 avenue Bernard Hirsch, CS 50105 Cergy, 95021 Cergy-Pontoise Cedex, France. Also affiliated with CEPR.

e-mail: pouyet@essec.edu.

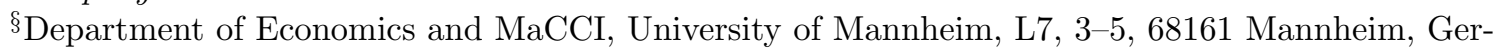
many. Also affiliated with CEPR.

e-mail:schutz@uni-mannheim.de. 


\section{J. HOMBERT, J. POUYET AND N. SCHUTZ}

\section{INTRODUCTION}

A SIGNIFICANT FRACTION OF MERGERS involve firms operating in vertically related markets (Fan and Goyal [2006]; Shenoy [2012]). Moreover, mergers - whether vertical

or not - tend to occur in waves (Mitchell and Mulherin [1996]; Gärtner and Halbheer [2009]; Ahern and Harford [2014]). While the industrial organization literature has devoted much attention to the potential anticompetitive effects of a single vertical merger (e.g., Ordover, Saloner and Salop [1990]; Nocke and White [2007]), little is known about the causes and consequences of waves of vertical mergers. ${ }^{1}$

In this paper, we build a model to study the (anti)competitive effects of, and the optimal policy response to, vertical merger waves. Consider as a motivating example the two merger proposals that Shell/DEA and BP/Veba submitted simultaneously to the European Commission in 2001. DEA and Veba were the only unintegrated producers of ethylene, an input used to produce ethylene derivatives. The main concern raised by the European Commission was that, by eliminating all unintegrated upstream firms, the proposed mergers would allow the newly vertically integrated firms to raise input prices when selling to their unintegrated downstream competitors. ${ }^{2}$

We argue that such mergers - or waves of mergers - which eliminate the last unintegrated upstream firm(s), can indeed have anticompetitive effects. ${ }^{3}$ Building on Bourreau et al. [2011], we study a vertically related industry initially populated by $M$ upstream firms and $N>M$ downstream firms. The game starts with a merger stage in which downstream firms can acquire upstream firms, potentially resulting in synergies. Next, upstream firms compete in prices to sell a homogeneous input to the remaining unintegrated downstream firms. Finally, downstream firms compete in prices with differentiated products. If fewer than $M$ mergers have taken place, the standard Bertrand logic applies and upstream competition drives the input price down to marginal cost.

By contrast, when all upstream firms are vertically integrated, upstream competition can result in a partial foreclosure equilibrium, i.e., an equilibrium in which the unintegrated downstream firms buy the input but at a price that exceeds marginal 


\section{ANTICOMPETITIVE VERTICAL MERGER WAVES}

cost. We show that, relative to upstream competition between unintegrated upstream firms and vertically integrated firms, upstream competition between vertically integrated firms can be quite soft for the following reason. A vertically integrated firm that has a high market share in the upstream market tends to be a soft competitor in the downstream market. This is because when that firm increases its downstream price, some of the consumers it loses in the downstream market start buying from unintegrated downstream firms, thereby raising input demand and thus upstream profits. Now, if a vertically integrated firm cuts its upstream price and steals upstream business from its vertically integrated rivals, then these rivals react by lowering their downstream prices since they now have lower upstream market shares and thus less of an incentive to be soft downstream competitors. This mechanism implies that undercutting in the upstream market is not always profitable.

In our model, firms may have incentives to merge vertically for two reasons. First, vertical mergers can give rise to synergies. Second, even when there are no synergies, firms have an incentive to integrate vertically if they expect that a wave of mergers eliminating all unintegrated upstream firms will result in partial foreclosure. In this case, both upstream and downstream firms have an incentive to merge, the former to sell the input above marginal cost, the latter to avoid buying the input above marginal cost. This leads to an equilibrium wave of vertical mergers in which every upstream firm integrates with a downstream firm and the remaining unintegrated downstream firms obtain the input at a high price.

We use the model to derive important insights on the optimal merger approval policy. We find that is is optimal to clear vertical mergers as long as they do not eliminate the last unintegrated upstream firm, as such mergers lead to lower downstream prices due to synergies and do not affect the input price (which remains equal to marginal cost).

By contrast, the last merger of the wave - the one that eliminates the last unintegrated upstream firm - calls for scrutiny because it can lead to a higher input price. That merger thus creates a tradeoff between merger-induced efficiencies and potential partial foreclosure effects. Interestingly, the simple rule-of-thumb according to which 


\section{J. HOMBERT, J. POUYET AND N. SCHUTZ}

the antitrust authority should be more favorable towards that merger if synergies are stronger can be misguided. This is because stronger synergies, which, everything else being equal, tend to make the merger more desirable, are also more conducive to partial foreclosure. We exhibit situations in which it is optimal to approve the last merger when synergies are weak and block it when synergies are strong.

Turning our attention to the role of upstream and downstream market structures, we find that the last merger of the wave is more likely to worsen market performance when the number of downstream firms is large relative to the number of upstream firms. ${ }^{4}$ The intuition is that the higher input price affects a larger fraction of the downstream industry when there are more downstream firms, so that partial foreclosure, when it arises, is more likely to affect market performance negatively. The degree of downstream product differentiation has more ambiguous effects: On the one hand, strategic effects are magnified when products are closer substitutes, making partial foreclosure easier to sustain; on the other hand, downstream products being closer substitutes results in fiercer downstream competition, implying that partial foreclosure is less likely to be detrimental to market performance when it arises.

We also study how the scope of vertical contracting interacts with the foreclosure effects of vertical mergers. First, we show that the last merger of the wave is less likely to result in partial foreclosure when price discrimination is allowed in the upstream market. Intuitively, price discrimination allows vertically integrated firms to undercut selectively in the upstream market, making deviations from the partial foreclosure equilibrium more profitable. Second, when upstream offers are secret or when upstream firms offer two-part tariffs, partial foreclosure is both less likely to arise and less likely to worsen market performance when it arises. These results suggest that antitrust authorities should be most cautious with regards to the last merger of the wave when upstream contracts are public, linear, and non-discriminatory.

Another contribution of our paper is to characterize fully the set of partial foreclosure equilibria in the merger-wave subgame. As in Bourreau et al. [2011], which our work builds on, we obtain monopoly-like equilibria in which one vertically integrated firm 


\section{ANTICOMPETITIVE VERTICAL MERGER WAVES}

sells the input to all unintegrated downstream firms at the monopoly upstream pricean outcome similar to Ordover, Saloner and Salop [1990]'s foreclosure outcome, but obtained without exogenous upstream commitment. In contrast to Bourreau et al. [2011], we also obtain collusive-like equilibria in which all vertically integrated firms sell the input at the same price above marginal cost and share the upstream market. Among collusive-like equilibria, the easiest to sustain are those with symmetric upstream market shares - an outcome similar to the collusive outcome in Nocke and White [2007], but obtained without repeated interactions.

The anticompetitive effects of vertical mergers have received much attention in the literature. The traditional vertical foreclosure theory, which was widely accepted by antitrust practitioners until the end of the 1960s, was challenged by the Chicago School in the 1970s (Posner [1976]; Bork [1978]). A more recent strategic approach initiated by Ordover, Saloner and Salop [1990] has established conditions under which vertical mergers relax competition. The main message conveyed in this strand of literature is that vertical mergers can lead to input foreclosure because upstream competition is softer between vertically integrated and unintegrated firms than among unintegrated firms only. However, this is based on specific assumptions, including extra commitment power for vertically integrated firms (Ordover, Saloner and Salop [1990]; Reiffen [1992]), choice of input specification (Choi and Yi [2000]), switching costs (Chen [2001]), tacit collusion (Nocke and White [2007]; Normann [2009]), exclusive dealing (Chen and Riordan [2007]), and information leakages (Allain, Chambolle and Rey [2016]). ${ }^{5}$ We show that if there are initially more downstream firms than upstream firms, then vertical merger waves that eliminate all unintegrated upstream firms can have severe anticompetitive effects even in the absence of such assumptions.

Two papers are more closely related to ours. Chen [2001] was the first to explore how a vertically integrated firm distorts its downstream pricing strategy when it supplies input to downstream rivals. This mechanism can result in an unintegrated upstream firm being unable to undercut the vertically integrated firm in the upstream market. By contrast, we show that when several vertically integrated firms are competing against 


\section{J. HOMBERT, J. POUYET AND N. SCHUTZ}

each other, vertically integrated firms are able to undercut, but not necessarily willing to do so. Bourreau et al. [2011] consider a special case of our model with an exogenous market structure. By contrast, we endogenize the market structure in a merger game with an arbitrary number of firms. This allows us to derive the optimal merger approval policy and study how it depends on the industry structure, the strength of synergies, and the scope of vertical contracting. We also endogenize the distribution of upstream market shares when several upstream firms set the same price, which allows us to identify a new class of (collusive-like) equilibria in which vertically integrated firms share the upstream market at a price above marginal cost. ${ }^{6}$

The rest of the paper is organized as follows. We describe the model in Section II and solve it in Section III. We analyze the optimal merger approval policy in Section IV. We present our results on the scope of vertical contracting in Section V. Section VI concludes. Omitted proofs can be found in the Appendix and in a separate Online Appendix (available on the Journal's editorial web site).

\section{MODEL}

Consider a vertically related industry with $M \geq 2$ identical upstream firms, $U_{1}, \ldots$, $U_{M}$, and $N \geq M+1$ symmetric downstream firms, $D_{1}, \ldots, D_{N}$. The upstream firms produce a homogeneous input at constant marginal cost $m$ and sell it to the downstream firms. The downstream firms can also obtain the input from an alternative source at constant marginal cost $\bar{m}>m .^{7}$ The downstream firms transform the intermediate input into a differentiated final product on a one-to-one basis at a constant unit cost which we normalize to zero. We assume throughout that the alternative source is a relevant outside option, in the sense that a downstream firm makes positive profits if it buys input at $\bar{m}$.

Downstream firms can merge with upstream firms. When $D_{k}$ merges with $U_{i}$, it produces the intermediate input in-house at unit cost $m$, its downstream unit transformation cost decreases by $\delta \in[0, m]$, and its downstream marginal cost therefore 


\section{ANTICOMPETITIVE VERTICAL MERGER WAVES}

becomes $m-\delta$. We say that mergers involve synergies if $\delta>0 .^{8}$

The downstream demand system is derived from Shubik and Levitan [1980]'s utility function:

$$
U=\sum_{k=1}^{\mathcal{N}} q_{k}-\frac{1}{2}\left(\sum_{k=1}^{\mathcal{N}} q_{k}\right)^{2}-\frac{\mathcal{N}}{2(1+\gamma)}\left(\sum_{k=1}^{\mathcal{N}} q_{k}^{2}-\frac{1}{\mathcal{N}}\left(\sum_{k=1}^{\mathcal{N}} q_{k}\right)^{2}\right)-\sum_{k=1}^{\mathcal{N}} p_{k} q_{k}
$$

where $q_{k}$ denotes consumption of $D_{k}$ 's product, $p_{k}$ is $D_{k}$ 's price, and $\gamma>0$ and $\mathcal{N} \geq N$ are parameters. Maximizing the utility function, we obtain the demand function ${ }^{9}$

$$
q_{k}=\frac{1+\gamma}{\frac{\mathcal{N}}{N}+\gamma} \frac{1}{N}\left(1-p_{k}-\gamma \frac{N}{\mathcal{N}}\left(p_{k}-\frac{\sum_{k^{\prime}=1}^{N} p_{k^{\prime}}}{N}\right)\right)
$$

Products become homogeneous as the substitutability parameter $\gamma$ tends to $\infty$, and independent as $\gamma$ approaches 0 . The parameter $\mathcal{N}$ is the number of varieties of the final good. Out of those $\mathcal{N}$ varieties, $N$ varieties are sold by the downstream firms, while the remaining $\mathcal{N}-N$ varieties are not available to consumers. ${ }^{10}$

The game unfolds in three stages. Stage 1 is the merger stage. First, all $N$ downstream firms bid simultaneously to acquire $U_{1}$, and $U_{1}$ decides which bid to accept, if any. Next, the remaining unintegrated downstream firms bid simultaneously to acquire $U_{2}$. This process goes on up to $U_{M} \cdot{ }^{11}$ We relabel firms as follows at the end of stage 1: If $K$ vertical mergers have taken place, then for all $1 \leq i \leq K, U_{i}$ is acquired by $D_{i}$ to form $U_{i}-D_{i}$, while $U_{K+1}, \ldots, U_{M}$, and $D_{K+1}, \ldots, D_{N}$ remain unintegrated.

In the second stage, each upstream firm $U_{i}\left(-D_{i}\right)$ announces the price $w_{i} \geq m$ at which it is willing to sell input to downstream firms. Next, each downstream firm $D_{k}$ privately observes the realization of a non-payoff-relevant, continuously- and independently-drawn random variable $\theta_{k}$. Unintegrated downstream firms will use the $\theta_{k} \mathrm{~s}$ to randomize their supplier choice, allowing us to ignore integer constraints on upstream market shares. ${ }^{12}$

In the third stage, downstream firms set their prices and, at the same time, each unintegrated downstream firm chooses its upstream supplier. ${ }^{13}$ We denote $D_{k}$ 's choice 


\section{J. HOMBERT, J. POUYET AND N. SCHUTZ}

of upstream supplier by $U_{s_{k}}\left(-D_{s_{k}}\right.$ if vertically integrated), $s_{k} \in\{0, \ldots, M\}$, with the convention that $U_{0}$ is the alternative source of input and $w_{0} \equiv \bar{m}$. Next, downstream demands are realized, production takes place, and payments are made to upstream suppliers. ${ }^{14}$

\section{EQUILIBRIUM ANALYSIS}

We look for pure-strategy subgame-perfect equilibria using backward induction.

\section{III(i). Equilibrium of stage 3}

Suppose $K$ mergers have taken place and let $w \equiv \min _{0 \leq i \leq M}\left\{w_{i}\right\}$ denote the lowest available input price. The profit of unintegrated downstream firm $D_{k}$ is:

$$
\pi_{k}=\left(p_{k}-w_{s_{k}}\right) q_{k}
$$

The profit of vertically integrated firm $U_{i}-D_{i}$ is:

$$
\pi_{i}=\left(p_{i}-m+\delta\right) q_{i}+\left(w_{i}-m\right) \sum_{k=K+1}^{N} 1\left[s_{k}=i\right] q_{k}
$$

where the first term is the profit earned in the downstream market and the second term is the profit earned from selling input to unintegrated downstream firms $D_{k}$ such that $s_{k}=i$.

We restrict attention to equilibria in which downstream firms do not condition their prices on the realization of the random variables $\theta_{k}$, i.e., firms do not randomize over prices. A strategy for unintegrated downstream firm $D_{k}$ is the choice of an input supplier as a function of $\theta_{k}$ and a downstream price, $\left(s_{k}(\cdot), p_{k}\right)$. A strategy for vertically integrated firm $U_{i}-D_{i}$ is a downstream price $p_{i}$. As $U_{i}-D_{i}$ does not know which downstream firms will select it as input supplier, it perceives its profit (3) as random. 


\section{ANTICOMPETITIVE VERTICAL MERGER WAVES}

Its expected profit is:

$$
E\left(\pi_{i}\right)=\left(p_{i}-m+\delta\right) q_{i}+\left(w_{i}-m\right) \sum_{k=K+1}^{N} \operatorname{Pr}\left[s_{k}\left(\theta_{k}\right)=i\right] q_{k}
$$

Consider first $D_{k}$ 's choice of input supplier. Clearly, $s_{k}($.$) is optimal if and only if$ for every realization of $\theta_{k}, s_{k}\left(\theta_{k}\right) \neq i$ whenever $w_{i}>w$. In words, $D_{k}$ buys at the lowest price.

We now turn to downstream pricing strategies for a given profile of optimal supplier choices $s$. As $D_{k}$ buys the input at price $w$, its first-order condition is:

$$
q_{k}+\left(p_{k}-w\right) \frac{\partial q_{k}}{\partial p_{k}}=0
$$

The first-order condition of vertically integrated firm $U_{i}-D_{i}$ is:

$$
q_{i}+\left(p_{i}-m+\delta\right) \frac{\partial q_{i}}{\partial p_{i}}+(w-m) \alpha_{i} \sum_{k=K+1}^{N} \frac{\partial q_{k}}{\partial p_{i}}=0
$$

where we have defined $U_{i}-D_{i}$ 's (expected) upstream market share as

$$
\alpha_{i} \equiv \frac{1}{N-K} \sum_{k=K+1}^{N} \operatorname{Pr}\left[s_{k}\left(\theta_{k}\right)=i\right]
$$

and we have used the fact that $\partial q_{k} / \partial p_{i}$ is a constant under linear demand. Equations (5)-(6) pin down a unique profile of prices $p^{s}$ such that $\left(s(),. p^{s}\right)$ is a Nash equilibrium of stage 3 .

Solving this (linear) system of equations, we show in the Appendix that the resulting equilibrium downstream prices depend on the profile of supplier choices $s$ only through the aggregate upstream market share of vertically integrated firms, $\bar{\alpha} \equiv \sum_{i=1}^{K} \alpha_{i}$, and, for vertically integrated firms, their own upstream market share. Formally, the price of an unintegrated downstream firm can be denoted by $P_{d}^{K}(w, \bar{\alpha})$, and that of a vertically integrated firm with upstream market share $\alpha_{i}$ by $P^{K}\left(w, \bar{\alpha}, \alpha_{i}\right)$. Moreover, those firms' 


\section{J. HOMBERT, J. POUYET AND N. SCHUTZ}

equilibrium profits can be written as $\Pi_{d}^{K}(w, \bar{\alpha})$ and $\Pi^{K}\left(w, \bar{\alpha}, \alpha_{i}\right)$, respectively.

Inspecting the first-order condition (6), we see that the outcome in the input market affects $U_{i}-D_{i}$ 's pricing incentives in the downstream market. The last term on the lefthand side shows that when $w>m$ and $\alpha_{i}>0, U_{i}-D_{i}$ has more of an incentive to raise its downstream price. Intuitively, when $U_{i}-D_{i}$ increases its downstream price, some of the consumers it loses in the final market start buying from unintegrated downstream firms that are themselves purchasing input from $U_{i}-D_{i}$, raising $U_{i}-D_{i}$ 's upstream profits. As this effect is stronger when $U_{i}-D_{i}$ commands a larger upstream market share, $U_{i}-D_{i}$ 's equilibrium downstream price is higher when $\alpha_{i}$ is larger.

Following the same logic, vertically integrated firms have more of an incentive to increase their downstream prices when $\bar{\alpha}$ is higher. By strategic complementarity, unintegrated downstream firms respond by setting higher prices as well. Summing up:

Lemma 1. Suppose $K$ mergers have taken place and the upstream price is $w>m$. When the upstream market share of a vertically integrated firm increases, its downstream price rises:

$$
\frac{\partial}{\partial \alpha_{i}} P^{K}\left(w, \bar{\alpha}, \alpha_{i}\right)>0 .
$$

Moreover, when the aggregate upstream market share of vertically integrated firms increases, all downstream prices rise:

$$
\frac{\partial}{\partial \bar{\alpha}} P^{K}\left(w, \bar{\alpha}, \alpha_{i}\right)>0, \quad \frac{\partial}{\partial \bar{\alpha}} P_{d}^{K}(w, \bar{\alpha})>0 .
$$

Proof. See the Appendix.

As discussed above, any distribution of market shares among the upstream firms offering $w$ can be sustained in an equilibrium of stage 3 . Lemma 1 implies that unintegrated downstream firms strictly prefer equilibria in which $\bar{\alpha}$ is highest because their rivals' downstream prices are highest: Formally, $\Pi_{d}^{K}(w, \bar{\alpha})$ is increasing in $\bar{\alpha}$. Unintegrated downstream firms are also indifferent among all the equilibria in which $\bar{\alpha}$ is 


\section{ANTICOMPETITIVE VERTICAL MERGER WAVES}

highest. This motivates the following (partial) selection criterion: When several upstream firms offer the lowest price and at least one of them is vertically integrated, firms play a Nash equilibrium of stage 3 in which all downstream firms purchase from vertically integrated firms, i.e., $\bar{\alpha}=1$.

\section{III(ii). Equilibrium of stage 2}

We consider first the case in which $K<M$ mergers took place in stage 1 , so that at least one unintegrated upstream firm remains. We then turn to the case in which all $M$ upstream firms integrated vertically. In the latter case, we say that a vertical merger wage has occurred.

\section{III(ii)(a). No merger wave}

In the Bertrand outcome (in the $K$-merger subgame), all downstream firms, vertically integrated or not, receive the input at marginal cost and set the corresponding equilibrium downstream prices. Equations (5)-(6) imply that these downstream prices do not depend on who supplies whom in the upstream market since the upstream margin, $w-m$, vanishes.

The Bertrand outcome is clearly an equilibrium of stage 2. It is also the only one. To see this, suppose the input is sold at $w>m$. If $w$ is offered by at least one vertically integrated firm, then all unintegrated downstream firms purchase from integrated firms by our selection criterion. Thus, unintegrated upstream firms make no profits and would rather undercut in the input market. If instead no vertically integrated firm offers $w$, then a vertically integrated firm would rather undercut in the input market, as such a deviation brings in upstream profits and raises the downstream prices of all rivals by Lemma $1 .{ }^{15}$ We have:

Lemma 2. After $K<M$ mergers, the Bertrand outcome is the only equilibrium. 


\section{J. HOMBERT, J. POUYET AND N. SCHUTZ}

III(ii)(b). Merger wave

Consider now the subgame with $K=M$ mergers. The argument in Section III(ii)(a) implies that in any equilibrium of stage 2 , at least one vertically integrated firm offers a price no greater than $\bar{m}$. The aggregate upstream market share of vertically integrated firms, $\bar{\alpha}$, is therefore equal to 1 in any equilibrium. ${ }^{16}$ In the following, we drop the argument $\bar{\alpha}$ and the superscript $K$ from equilibrium pricing and profit functions to ease notation.

The Bertrand outcome remains an equilibrium:

Lemma 3. After $M$ mergers, the Bertrand outcome is an equilibrium.

The Bertrand outcome is, however, not necessarily the only equilibrium. We now look for equilibria involving partial foreclosure, that is, equilibria in which unintegrated downstream firms purchase the input, but at a price that strictly exceeds marginal cost.

To see why partial foreclosure can be sustained in equilibrium, suppose the lowest input price strictly exceeds marginal cost, $w>m$, and let us investigate whether vertically integrated firm $U_{i}-D_{i}$ would benefit from expanding its upstream market share $\alpha_{i}$. Specifically, suppose $\alpha_{i}$ increases by $d \alpha_{i}>0, \alpha_{j}$ decreases by $d \alpha_{i}$ for some $j \neq i$, and the market shares of other vertically integrated firms remain constant. ${ }^{17}$ As $\alpha_{i}$ increases, $U_{i}-D_{i}$ 's profits in the upstream market rise mechanically-the upstream profit effect. But on the other hand, since $\alpha_{j}$ falls, Lemma 1 implies that $U_{j}-D_{j}$ decreases its downstream price, lowering $U_{i}-D_{i}$ 's profits - the loss of the softening effect.

Formally, the change in $U_{i}-D_{i}$ 's equilibrium profits is given by

$$
d E\left(\pi_{i}\right)=\underbrace{(N-M)(w-m) Q_{d} d \alpha_{i}}_{\text {Upstream profit effect }(>0)}+\underbrace{\frac{\partial P\left(w, \alpha_{j}\right)}{\partial \alpha_{j}} \frac{\partial E\left(\pi_{i}\right)}{\partial p_{j}}\left(-d \alpha_{i}\right)}_{\text {Softening effect }(<0 \text { by Lemma } 1)},
$$

where we have used the envelope theorem and the fact that the equilibrium downstream prices of firms other than $U_{i}-D_{i}$ and $U_{j}-D_{j}$ do not change, and $Q_{d}$ represents the 


\section{ANTICOMPETITIVE VERTICAL MERGER WAVES}

equilibrium output of an individual unintegrated downstream firm. If the softening effect dominates the upstream profit effect, then $U_{i}-D_{i}$ would rather not expand its market share. As we shall see below, this mechanism can give rise to partial foreclosure.

Monopoly-like equilibria. Several types of partial foreclosure outcomes can be sustained in equilibrium. A first natural candidate is the monopoly-like outcome, in which a single vertically integrated firm supplies the upstream market at the monopoly upstream price, denoted $w_{m} \equiv \arg \max _{w \leq \bar{m}} \Pi(w, 1)$, while the other vertically integrated firms make no upstream offers (or, equivalently, offer prices above $\bar{m}$ ). It is easily checked that $w_{m}$ is unique and that monopoly power gives rise to a positive upstream $\operatorname{markup}\left(w_{m}>m\right)$.

To see why such an outcome may be sustainable in equilibrium, suppose $U_{i}-D_{i}$ sets $w_{m}$ while $U_{j}-D_{j}$ stays out of the upstream market for every $j \neq i$. First, $U_{i}-D_{i}$ does not want to set a different price or withdraw its offer by the definition of $w_{m}$ and the argument in Section III(ii)(a). Second, $U_{j}-D_{j}$ may not want to undercut $w_{m}$ as the softening effect may well dominate the upstream profit effect. Formally, undercutting is not profitable if

$$
\Pi\left(w_{m}, 1\right) \leq \Pi\left(w_{m}, 0\right)
$$

Thus, monopoly-like equilibria exist if and only if condition (7) holds.

Those equilibria provide a foundation for Ordover, Saloner and Salop [1990]'s assumption that a vertically integrated firm commits to exiting the upstream market and letting its upstream rival set the monopoly upstream price. Our analysis reveals that no commitment is needed when upstream rivals are vertically integrated and the softening effect is strong.

Collusive-like equilibria. The second type of partial foreclosure outcomes are collusivelike outcomes, in which several vertically integrated firms offer the lowest input price $w>m$. Recall that in stage 3 , any distribution of upstream market shares $\left(\alpha_{i}\right)_{1 \leq i \leq M}$ 


\section{J. HOMBERT, J. POUYET AND N. SCHUTZ}

such that $\sum_{i=1}^{M} \alpha_{i}=1$ and $\alpha_{j}=0$ whenever $w_{j}>w$ can be sustained in equilibrium.

Consider such a collusive-like outcome $\left(w,\left(\alpha_{i}\right)_{1 \leq i \leq M}\right)$. A vertically integrated firm $U_{i}-D_{i}$ with $\alpha_{i}>0$ can deviate in two ways: By increasing its input price and exiting the upstream market, thereby benefiting from a stronger softening effect but forgoing upstream profits; or by pricing below $w$ and taking over the upstream market, thereby benefiting from a positive upstream profit effect but losing the softening effect. The only possible deviation for a vertically integrated firm $U_{i}-D_{i}$ with $\alpha_{i}=0$ is to price below $w$, which involves the same tradeoff. Taking stock, the collusive-like outcome is an equilibrium if and only if:

$$
\Pi\left(w, \alpha_{i}\right) \geq \max \left\{\max _{\widetilde{w} \leq w} \Pi(\widetilde{w}, 1), \Pi(w, 0)\right\}, \quad \text { for all } i \in\{1, \ldots, M\}
$$

Equation (8) is satisfied when the softening effect is strong enough so that undercutting is not profitable, but not too strong so that exiting is not profitable either.

Symmetric collusive-like equilibria, where all vertically integrated firms set the same price $w>m$ and obtain the same market share $1 / M$, are a special case of interest. They play a special role because, among collusive-like equilibria, the symmetric ones are easiest to sustain. This follows as a vertically integrated firm's profit $\Pi\left(w, \alpha_{i}\right)$ is concave in its upstream market share $\alpha_{i}$ (see Lemma 6 in the Appendix). Thus, if condition (8) holds for some distribution of market shares, then it also holds for symmetric market shares. Intuitively, making market shares more symmetric raises the profit of the firm that earns the least, and thus lessens the deviation incentives of the firm that would gain the most from deviating. We have:

Lemma 4. If there is a collusive-like equilibrium at upstream price $w>m$, then there is also a symmetric collusive-like equilibrium at that price.

In a symmetric collusive-like equilibrium, all vertically integrated firms set the same input price above cost and share the upstream market equally, as in models of collusion. Nocke and White [2007] obtain similar upstream outcomes in a repeated-game frame- 


\section{ANTICOMPETITIVE VERTICAL MERGER WAVES}

work with a market structure similar to ours. Our analysis reveals that these outcomes can actually be sustained in a one-shot game when all upstream firms are vertically integrated.

Complete equilibrium characterization. Lemma 4 implies that, when looking for a partial foreclosure equilibrium other than the monopoly-like equilibrium, it is enough to focus on symmetric collusive-like equilibria. This means that partial foreclosure equilibria exist if and only if condition (7) holds or condition (8) holds for some $w>m$ and $\alpha_{i}=1 / M$. Building on this, we can now provide necessary and sufficient conditions on the strength of synergies, $\delta$, for the existence of partial foreclosure equilibria in the $M$-merger subgame: ${ }^{18}$

Proposition 1. There exist three thresholds $\delta_{m}, \underline{\delta}_{c}$, and $\bar{\delta}_{c}$ satisfying $\underline{\delta}_{c} \leq \delta_{m}<\bar{\delta}_{c}$ and such that after $M$ mergers: ${ }^{19}$

- Monopoly-like equilibria exist if and only if $\delta \geq \delta_{m}$.

- Symmetric collusive-like equilibria exist if and only if $\underline{\delta}_{c} \leq \delta<\bar{\delta}_{c}$. The set of prices that can be sustained in a symmetric collusive-like equilibrium is an interval.

- The Bertrand outcome is always an equilibrium, and it is the only one if $\delta<\underline{\delta}_{c}$.

Proof. See our Online Appendix (Section B) on the Journal's editorial web site.

The cutoffs defined in Proposition 1 reflect the tradeoff between the upstream profit effect and the softening effect. Consider first the condition for monopoly-like equilibria: Such equilibria exist provided synergies are strong enough. Intuitively, as the cost differential between unintegrated and integrated firms widens, the output of the former firms declines and upstream profits shrink. The magnitude of the softening effect, which works at the margin and reflects the upstream suppliers' willingness to raise their input demand, is not directly affected. As undercutting decisions trade off the upstream profit 


\section{J. HOMBERT, J. POUYET AND N. SCHUTZ}

effect against the softening effect, it becomes more attractive to stay out of the input market as $\delta$ increases.

Consider next the existence condition for collusive-like equilibria. The two thresholds on $\delta$ come from the two terms on the right-hand side of condition (8). First, to make undercutting unprofitable, the upstream profit effect should not be too strong relative to the softening effect - this arises when synergies are strong enough. Second, to make exiting unprofitable, the softening effect should not be too strong relative to the upstream profit effect - this arises when synergies are not too strong. Proposition 1 also states that there exists a continuum of symmetric collusive-like equilibria parameterized by the input price. This comes from the fact that condition (8) is an inequality: If the inequality holds strictly for some $w$, then it also holds in a neighborhood of $w$ by continuity.

The inequalities $\underline{\delta}_{c} \leq \delta_{m}<\bar{\delta}_{c}$ follow by concavity of $\Pi\left(w, \alpha_{i}\right)$ in $\alpha_{i}$. To see this, suppose the existence condition for a monopoly-like equilibrium is just satisfied, $\delta=\delta_{m}$, so that the non-deviation constraint $(7)$ is binding, $\Pi\left(w_{m}, 1\right)=\Pi\left(w_{m}, 0\right)$. By concavity, we have the following inequality:

$$
\Pi\left(w_{m}, 1 / M\right) \geq \min \left\{\Pi\left(w_{m}, 1\right), \Pi\left(w_{m}, 0\right)\right\}=\Pi\left(w_{m}, 1\right)=\Pi\left(w_{m}, 0\right) .
$$

Hence, there also exists a symmetric collusive-like equilibrium with input price $w_{m}$. From this, we can conclude that collusive-like equilibria are easier to sustain when $\delta$ is intermediate, whereas monopoly-like equilibria are easier to sustain when $\delta$ is large.

Monopoly-like equilibria were studied by Bourreau, Hombert, Pouyet, and Schutz [2011], henceforth BHPS, in a similar setting. One novelty of the present paper is to uncover the existence of collusive-like equilibria. In particular, symmetric collusive-like equilibria stand out because they are the easiest to sustain. In those equilibria, all vertically integrated firms set the same input price and receive the same upstream market share. By contrast, BHPS characterize another class of equilibria, which they call matching-like equilibria, in which all vertically integrated firms set the same input price 


\section{ANTICOMPETITIVE VERTICAL MERGER WAVES}

and one of them receives a market share of $1 .^{20}$ By Proposition 4 in BHPS, matchinglike equilibria are always unstable and Pareto dominated. An outside observer seeing that vertically integrated firms are all setting the same price would thus conclude from BHPS that those firms are playing the Bertrand equilibrium. By contrast, symmetric collusive-like equilibria can be both stable and Pareto efficient from the vertically integrated firms' point of view. ${ }^{21}$ Our analysis thus reveals that several vertically integrated firms setting the same price may in fact be a symptom of partial foreclosure in the input market.

\section{III(iii). Equilibrium of stage 1}

Combining Lemma 2 and Proposition 1 yields:

Proposition 2. Suppose $\delta>0$. All equilibria involve a merger wave. If in addition $\delta \geq \underline{\delta}_{c}$, then there exist equilibria in which partial foreclosure occurs, as well as equilibria in which the Bertrand outcome arises. If instead $\delta<\underline{\delta}_{c}$, then the Bertrand outcome arises.

In the special case where $\delta=0$, any number of mergers can be sustained in equilibrium. Equilibria with $M$ mergers and partial foreclosure exist if $\underline{\delta}_{c}=0$. Otherwise, all equilibria involve the Bertrand outcome.

When the existence condition for monopoly-like or symmetric collusive-like equilibria holds, a vertical merger raises the joint profits of the merging parties: Firms merge to implement a partial foreclosure equilibrium and, when $\delta>0$, to enjoy efficiency gains.

The case $\delta=0$ illustrates that vertical mergers are strategic complements. If the Bertrand outcome is expected after $M$ mergers, then unintegrated downstream firms and vertically integrated firms earn the same profit in every subgame since there are no synergies. As a result, firms have no incentive to merge, and there always exists an equilibrium with no merger and the Bertrand outcome in the upstream market. 


\section{J. HOMBERT, J. POUYET AND N. SCHUTZ}

Conversely, when firms expect partial foreclosure to arise after $M$ mergers, a merger wave occurs for purely anticompetitive reasons. The last merger is profitable only if the first $M-1$ upstream firms have merged before. By the same token, the first merger is profitable only because the merger partners anticipate that it will be followed by $M-1$ counter-mergers. ${ }^{22}$

We conclude this section by discussing which firms are likely to gain or lose from a vertical merger wave resulting in partial foreclosure. We rely on the following equilibrium selection to simplify the analysis: In every $M$-merger subgame, regardless of who has merged with whom, a symmetric collusive-like equilibrium at price $w>m$ is played. Under this selection, all equilibrium winning bids are equal to $\Pi(w, 1 / M)-\Pi_{d}(w, 1 / M)$. The owners of downstream firms end up with a net payoff of $\Pi_{d}(w, 1 / M)$, whereas the upstream firms' original owners receive a net payoff of $\Pi(w, 1 / M)-\Pi_{d}(w, 1 / M)$. Therefore, upstream firms' owners clearly gain from the merger wave, whereas all downstream firms' owners suffer from it. The reason is that the sequence of auctions that takes place in stage 1 involves negative externalities between buyers: When a downstream firm integrates backward, other unintegrated downstream firms suffer because of both synergies and partial foreclosure. ${ }^{23}$

\section{MERGER POLICY}

We now study the optimal merger policy. The antitrust authority's objective function is

$$
W=(1-\lambda) \times(\text { Consumer surplus })+\lambda \times(\text { Industry profit }+ \text { Consumer surplus })
$$

where $\lambda \in[0,1]$ is a parameter. Note that $W$ is consumer surplus when $\lambda=0$ and aggregate surplus when $\lambda=1$. We say that a vertical merger improves (resp., worsens) market performance if it raises (resp., reduces) $W$. We assume throughout that $\delta>0$ so that, by Proposition 2, a vertical merger wave arises in any equilibrium and, in 


\section{ANTICOMPETITIVE VERTICAL MERGER WAVES}

principle, vertical mergers can give rise to a tradeoff between efficiency and foreclosure effects. $^{24}$

We first argue that the first $M-1$ mergers of the wave should always be approved, and that the $M$-th merger should be approved as well if it does not result in partial foreclosure:

Lemma 5. Regardless of $\lambda$, each of the first $M-1$ mergers improves market performance. The same holds true for the last merger provided the input continues to be priced at cost.

Proof. See our Online Appendix (Section D) on the Journal's editorial web site.

Consider the $K$-th merger of the wave with $K<M$. By Lemma 2, the input is sold at marginal cost both pre- and post-merger. The only firm directly affected by the merger is thus $D_{k}$, whose downstream marginal cost decreases by $\delta$ due to synergies. That firm responds by reducing its downstream price, and its downstream rivals follow suit by strategic complementarity. The merger thus raises consumer surplus. It also raises aggregate surplus as it reduces $D_{k}$ 's production costs, lowers rival firms' markups, and shifts output away from the less efficient unintegrated downstream firms. Since our market performance measure $W$ is a convex combination of consumer surplus and aggregate surplus, it is also positively affected by the merger. For the same reasons, the last merger of the wave also improves market performance if the Bertrand outcome continues to prevail post-merger.

Combining Proposition 2 and Lemma 5, we can conclude that the antitrust authority should approve all mergers if $\delta<\underline{\delta}_{c}$, i.e., provided synergies are sufficiently weak. If instead $\delta \geq \underline{\delta}_{c}$, then the first $M-1$ mergers should be approved by Lemma 5 , but the approval decision for the last merger of the wave involves a tradeoff between the merger's efficiency and foreclosure effects. In the remainder of the section, we study this tradeoff in detail. 


\section{J. HOMBERT, J. POUYET AND N. SCHUTZ}

We start by studying the impact of the last merger on market performance in the case where $M=2$ and $N=3$, as this special case is sufficiently tractable to permit analytical proofs. We will later study other market structures using numerical simulations.

When $\delta>\underline{\delta}_{c}$, the $M$-merger subgame has multiple equilibria. We will use the following selection criteria alternatively: $(\mathcal{C})$ If $\delta \in\left[\underline{\delta}_{c}, \bar{\delta}_{c}\right)$, then the symmetric collusive-like equilibrium that maximizes the vertically integrated firms' profits is played; otherwise, the Bertrand outcome arises; and $(\mathcal{M})$ if $\delta \geq \delta_{m}$, then a monopoly-like equilibrium is played; otherwise, the Bertrand outcome arises. The following proposition characterizes the optimal merger policy as a function of the strength of synergies $(\delta)$, the degree of substitutability between downstream products $(\gamma)$, and the welfare weight $(\lambda)$ :

Proposition 3. Consider the case where $M=2$ and $N=3$ :

- Under selection criterion $(\mathcal{C})$, there exist $\gamma_{c}$ and $\delta_{c}^{W}$ such that the second merger worsens market performance if and only if $\gamma>\gamma_{c}$ and $\delta \in\left[\underline{\delta}_{c}, \delta_{c}^{W}\right)$.

- Under selection criterion $(\mathcal{M})$, there exist $\gamma_{m}$ and $\delta_{m}^{W}$ such that the second merger worsens market performance if and only if $\gamma>\gamma_{m}$ and $\delta \in\left[\delta_{m}, \delta_{m}^{W}\right)$.

Moreover, $\delta_{c}^{W}$ and $\delta_{m}^{W}$ are decreasing in $\gamma$ and $\lambda$, and $\underline{\delta}_{c}$ and $\delta_{m}$ are decreasing in $\gamma$.

Proof. See our Online Appendix (Section E) on the Journal's editorial web site.

[Insert Figure 1 here]

Figure 1 provides a graphical representation of Proposition 3 under both selection criteria $(\mathcal{C})$ (left panels) and $(\mathcal{M})$ (right panels), assuming the antitrust authority has a consumer surplus standard $(\lambda=0$, top panels) or an aggregate surplus standard $(\lambda=1$, bottom panels $) .{ }^{25}$ Several observations are in order. First, the dark-grayshaded area in the top panels is a subset of that in the bottom panels, implying that the antitrust authority is more likely to clear the second merger if it has an aggregate surplus standard than if it has a consumer surplus standard. Intuitively, the partial 


\section{ANTICOMPETITIVE VERTICAL MERGER WAVES}

foreclosure effects that arise when $\delta \geq \underline{\delta}_{c}$ (top panels) or $\delta \geq \delta_{m}$ (bottom panels) tend to raise industry profitability, which the antitrust authority weighs positively when $\lambda=1$ but not when $\lambda=0$.

Second, the simple rule-of-thumb according to which the antitrust authority should be more favorable towards a merger when synergies are stronger can be misguided. For example, when $\gamma$ is high in the top-right panel, the merger should be approved when synergies are weak (low $\delta$ ), whereas it should be blocked when synergies are strong (high $\delta)$. Intuitively, while larger efficiency gains improve market performance for a given outcome in the input market, they also increase the likelihood of input foreclosure. In fact, the optimal merger policy is not necessarily monotonic in the strength of synergies. For example, when $\gamma$ is close to 10 in the top-left panel, it is optimal to approve the second merger when $\delta$ is small or large, but prohibit it when $\delta$ is intermediate.

Third, the optimal merger policy also depends in subtle ways on the intensity of downstream competition, as measured by the substitutability parameter $\gamma$. Note first that the thresholds $\underline{\delta}_{c}$ and $\delta_{m}$, which delineate the light-gray-shaded area in the left and right panels, are both decreasing in $\gamma$. Hence, for fixed $\delta$ and regardless of the selection criterion, partial foreclosure is more likely to arise after the second merger if products are closer substitutes. ${ }^{26}$ Intuitively, when $\gamma$ is high, a vertically integrated firm that supplies (part of) the upstream market is reluctant to set too low of a downstream price since this would strongly contract its upstream profit. The other vertically integrated firms benefit from a substantial softening effect and, as a result, are not willing to undercut in the upstream market.

It is useful to relate this comparative statics result to the European Commission's non-horizontal merger guidelines (EC [2007]). In those guidelines, the Commission argues that vertically integrated firms have less of an incentive to foreclose when premerger downstream margins are low, because those firms would not find it profitable to forgo upstream revenues to preserve low downstream profits. ${ }^{27}$ The Commission also emphasizes that, when assessing the potential anti-competitive effect of a vertical merger, the vertically integrated firms' ability to foreclose should be distinguished from 


\section{J. HOMBERT, J. POUYET AND N. SCHUTZ}

their incentives to foreclose. Our model, which focuses on the ability to foreclose, shows that if pre-merger downstream margins are low because final products are close substitutes, then vertically integrated firms are in fact better able to sustain an equilibrium with partial foreclosure.

The substitutability parameter $\gamma$ also has a negative impact on the thresholds $\delta_{c}^{W}$ and $\delta_{m}^{W}$, which separate the black-shaded area from the dark-gray-shaded one in the left and right panels. Hence, for fixed $\delta$ and starting from a $\gamma$ that gives rise to partial foreclosure, an increase in $\gamma$ makes it more likely that the second merger improves market performance. Intuitively, when final products are close substitutes, the passthrough rate of synergies tends to be higher and the input price charged in a partial foreclosure equilibrium tends to be lower, making it less likely that the second merger raises final prices and worsens market performance. The general picture that emerges is again one where the optimal merger policy is not necessarily monotonic in the degree of downstream substitutability. For example, when $\delta$ is close to 0.05 in the top right panel, it is optimal to clear the second merger when $\gamma$ is small or large, but block it when $\gamma$ is intermediate.

The role of upstream and downstream concentration. We now study how the number of upstream and downstream firms, $M$ and $N$, affect the optimal policy towards the last merger of the wave. Our goal here is not to provide an exhaustive treatment of the issue, but rather to highlight the main forces at work. We do so by way of numerical simulations. For the sake of brevity we use selection criterion $(\mathcal{C})$ exclusively from now on.

\section{[Insert Figure 2 here]}

Downstream concentration. Figure 2 provides a graphical representation of the optimal policy towards the last merger for $M=2$ and $N=3$, 4, and 5 (from left to right) - the left panels replicate the top panels of Figure 1. A first observation is that the general picture is very similar to the one described in Proposition 3. Regardless of 


\section{ANTICOMPETITIVE VERTICAL MERGER WAVES}

whether the antitrust authority has a consumer surplus (top panels) or an aggregate surplus (bottom panels) standard, the following still holds: An antitrust authority with a consumer surplus standard is less likely to approve a merger than one with an aggregate surplus standard; stronger synergies (resp. more substitutable downstream

products) facilitate partial foreclosure, but also tend to make such partial foreclosure less detrimental to market performance.

Comparing the various panels in Figure 2, we can determine how downstream concentration affects the optimal merger policy. We see that an increase in $N$ raises $\underline{\delta}_{c}$, the threshold that delineates the light-gray-shaded area, albeit only marginally so. This suggests that partial foreclosure is less likely to arise when the downstream industry is less concentrated, although further numerical simulations show that this result very much depends on the specific values of $M, N$, and $\gamma$.

More notably, an increase in $N$ shifts the thresholds $\delta_{c}^{W}$ upwards, and significantly so, implying that the range of synergies and substitutability parameters under which the last merger worsens market performance expands as $N$ increases. As further numerical simulations show, this latter effect is robust. Intuitively, partial foreclosure is more detrimental to market performance when $N$ is higher since the high input price affects a larger fraction of the downstream competitors. The main message we take away from this comparison is that antitrust authorities should be more cautious with regards to the last merger when the number of downstream competitors is high relative to the number of upstream competitors. ${ }^{28}$

[Insert Figure 3 here]

Upstream concentration. Figure 3 represents graphically the optimal policy towards the last merger for $N=5$ and $M=2,3$, and 4 . Again, the broad picture is similar to the one described by Proposition 3.

Comparing the various panels, we see that an increase in $M$ tends to raise $\underline{\delta}_{c}$, implying that partial foreclosure is harder to sustain in equilibrium when there are more upstream competitors. We also see that as $M$ increases, the black-shaded area shrinks 


\section{J. HOMBERT, J. POUYET AND N. SCHUTZ}

markedly and even disappears in some of the panels. This suggest that when partial foreclosure equilibria arise, they are less likely to be detrimental to market performance when there are more upstream competitors. The intuition is that the high input price affects a smaller fraction of the downstream industry when $M$ is high relative to $N$. The takeaway here is that the antitrust authority should be more willing to clear the last merger if there is sufficient upstream competition.

\section{DISCRIMINATION, TWO-PART TARIFFS, AND SECRET OFFERS}

This section studies the interplay between the scope of vertical contracting and the foreclosure effects of mergers. The general message that emerges is that merger waves are more likely to harm competition if, as in our baseline model, upstream contracts are non-discriminatory, linear, and public.

\section{V(i). Discrimination}

We now allow upstream firms to third-degree price discriminate in the input market. It is easily checked that the Bertrand outcome remains an equilibrium of the upstream competition subgame, regardless of how many mergers took place in stage 1 . The following proposition asserts that after a merger wage, monopoly-like and collusive-like equilibria continue to exist, but under conditions that are more stringent than under uniform pricing:

Proposition 4. Suppose firms can price discriminate in the input market. There exist thresholds $N_{m}^{d}, \delta_{m}^{d}$, and $\underline{\delta}_{c}^{d}$ satisfying $N_{m}^{d}>M+3, \delta_{m}^{d} \geq \delta_{m}$, and $\underline{\delta}_{c}^{d} \in\left[\underline{\delta}_{c}, \bar{\delta}_{c}\right]$, and such that, after $M$ mergers:

- Monopoly-like equilibria exist if and only if $N \leq N_{m}^{d}$ and $\delta \geq \delta_{m}^{d}$. The monopoly upstream price is the same as under uniform pricing. 


\section{ANTICOMPETITIVE VERTICAL MERGER WAVES}

- Symmetric collusive-like equilibria exist if $\underline{\delta}_{c}^{d} \leq \delta \leq \bar{\delta}_{c}$. Moreover, if an input price can be sustained in a symmetric collusive-like equilibrium under discrimination, then it can also be sustained under uniform pricing.

Proof. See our Online Appendix (Section G) on the Journal's editorial website.

The reason why price discrimination makes partial foreclosure harder to sustain is that it allows vertically integrated firms to cut input prices selectively when they deviate from a partial foreclosure equilibrium, raising the maximum deviation profit they can attain. For instance, suppose monopoly like equilibria exist under uniform pricing, which arises when $\Pi\left(w_{m}, 1\right) \leq \Pi\left(w_{m}, 0\right)$. Under discrimination, assuming $N>M+1$, a vertically integrated firm that does not supply the input market can achieve a deviation profit larger than $\Pi\left(1, w_{m}\right)$ by offering a price slightly below $w_{m}$ to a single unintegrated downstream firms. That this deviation results in larger profits follows by concavity as

$$
\Pi\left(w_{m}, \frac{1}{N-M+1}\right)>\min \left\{\Pi\left(w_{m}, 0\right), \Pi\left(w_{m}, 1\right)\right\}=\Pi\left(w_{m}, 1\right) .
$$

Proposition 4 sheds some light on the debate on the enforcement of anti-discrimination laws (such as the Robinson-Patman Act in the U.S. and Article 102(c) of the Treaty on the Functioning of the European Union) in intermediate goods markets. The extant literature (see Katz [1987]; DeGraba [1990]; Yoshida [2000]; Inderst and Valletti [2009]; Inderst and Shaffer [2009]) focuses on market structures with an upstream bottleneck. In our framework with upstream competition, price discrimination induces upstream firms to compete head-to-head for each downstream buyer, which tends to lower both upstream and downstream prices. This result echoes Corts [1998]'s findings that, in a setting without vertical relations, third-degree price discrimination can lead to all-out competition and lower all prices. 


\section{J. HOMBERT, J. POUYET AND N. SCHUTZ}

V(ii). Two-part tariffs

We now assume that upstream firms compete in two-part tariffs, and denote by $\left(w_{i}, T_{i}\right)$ the contract offered by $U_{i}$. We confine attention to non-negative fixed parts: $T_{i} \geq 0 .{ }^{29}$ For technical reasons explained in our Online Appendix (Section H), we assume that input suppliers are chosen before downstream competition takes place and focus first on the case $N=M+1$. In that Appendix, we also argue that the Bertrand outcome, in which the input is supplied at $(w, T)=(m, 0)$, remains an equilibrium of the upstream competition subgame regardless of how many mergers took place in stage 1.

Consider now the $M$-merger subgame. The monopoly contract solves

$$
\left(w_{m}^{t p}, T_{m}^{t p}\right) \equiv \arg \max _{(w, T)} \Pi(w, 1)+T \quad \text { s.t. } \quad \Pi_{d}(w)-T \geq \bar{\pi}_{d}
$$

where $\bar{\pi}_{d}$ denotes the profit of the unintegrated downstream firm when it buys the input from the alternative source. It is easily checked that the monopoly contract is unique and $w_{m}^{t p}>m$. Intuitively, the upstream supplier wants to raise the unintegrated downstream firm's marginal cost as this limits the cannibalization of its own downstream sales and softens downstream competition (see, e.g., Bonanno and Vickers [1988]).

We define a monopoly-like outcome as a situation in which the unintegrated downstream firm accepts a contract with a variable part of $w_{m}^{t p}$. Since $w_{m}^{t p}>m$, the softening effect is at work, lessening undercutting incentives in the upstream market and potentially giving rise to monopoly-like equilibria. We have:

Proposition 5. Suppose $N=M+1$. Under two-part tariffs, there exists $\delta_{m}^{t p}>\delta_{m}$ such

that after $M$ mergers, monopoly-like equilibria exist if and only if $\delta \geq \delta_{m}^{t p}$. Moreover, $w_{m}^{t p}<w_{m}$

Proof. See our Online Appendix (Section H.1) on the Journal's editorial web site.

Thus, compared to linear tariff competition, the monopoly-like outcome is both less harmful to consumers $\left(w_{m}^{t p}<w_{m}\right.$, resulting in lower downstream prices) and harder to 


\section{ANTICOMPETITIVE VERTICAL MERGER WAVES}

sustain $\left(\delta_{m}^{t p}>\delta_{m}\right)$ under two-part pricing. The intuition for $w_{m}^{t p}<w_{m}$ is the usual reduction in double marginalization associated with two-part pricing. The inequality $\delta_{m}^{t p}>\delta_{m}$ follows as $w_{m}^{t p}<w_{m}$, implying that the softening effect is weaker under twopart pricing.

We close this subsection by providing a sufficient condition for the existence of collusive-like equilibria in another special case:

Proposition 6. Suppose $M=2$ and $N=4$. Under two-part tariffs, there exist $\underline{\delta}_{c}^{t p}$ and $\bar{\delta}_{c}^{t p}$ such that after $M$ mergers, symmetric collusive-like equilibria exist if $\underline{\delta}_{c}^{t p} \leq \delta \leq \bar{\delta}_{c}^{t p}$.

Proof. See our Online Appendix (Section H.2) on the Journal's editorial web site.

V(iii). Secret offers

We now assume that upstream firms offer linear and secret contracts. As non-discriminatory input prices would be de facto observed by all downstream firms, we allow upstream firms to third-degree price discriminate as in Section V(i). For technical reasons explained in our Online Appendix (Section I), we assume that input suppliers are chosen before downstream competition takes place and that supplier choices are publicly observed (i.e., everybody knows who purchases from whom, but not on what terms). We look for perfect Bayesian equilibria. It is easily checked that the Bertrand outcome remains an equilibrium regardless of how many mergers took place in stage 1. Such an equilibrium can be supported, e.g., by passive beliefs, as argued in our Online Appendix..$^{30}$

Next, we consider the $M$-merger subgame, focusing on the case $N=M+1$ for simplicity. To define the monopoly upstream price under secret offers, suppose $U_{i}-D_{i}$ supplies $D_{M+1}$ at price $w$, but all other firms believe the upstream price is $w^{b}$. Those firms set the downstream price they would charge under public offers when $U_{i}-D_{i}$ supplies the upstream market at price $w^{b}$. In this branch of the game tree, everything works as if $U_{i}-D_{i}$ and $D_{M+1}$ were playing a two-player game with common knowledge of 


\section{J. HOMBERT, J. POUYET AND N. SCHUTZ}

the upstream price and of the prices set by the other firms. Let $\Pi^{s}\left(w, w^{b}\right)$ and $\Pi_{d}^{s}\left(w, w^{b}\right)$ denote the resulting equilibrium profits of $U_{i}-D_{i}$ and $D_{M+1}$. The monopoly upstream price under secret offers, $w_{m}^{s}$, is such that $U_{i}-D_{i}$ does want to set $w_{m}^{s}$ when other integrated firms believe the upstream price is $w_{m}^{s}$ : Formally, $w_{m}^{s}=\arg \max _{w} \Pi^{s}\left(w, w_{m}^{s}\right)$. We show that $w_{m}^{s}$ is unique and $w_{m}^{s}>m$.

Consider the monopoly-like outcome in which $U_{i}-D_{i}$ offers $w_{m}^{s}$ and other vertically integrated firms make no upstream offer. To study $U_{j}-D_{j}$ 's incentives to take over the upstream market requires to specify how other firms update their beliefs if they find out that $U_{j}-D_{j}$ has become the upstream supplier. We refine these out-of-equilibrium beliefs using forward induction. ${ }^{31}$ When other firms observe that $D_{M+1}$ deviates and purchases the input from $U_{j}-D_{j}$, they perceive the deviation as a consequence of $D_{M+1}$ and $U_{j}-D_{j}$ 's optimizing behavior. They thus believe that $U_{j}-D_{j}$ has offered a price that maximizes its deviation profit subject to $D_{M+1}$ accepting the deviating offer. Formally, the optimal deviation price, $w_{j}^{b}$, must solve the fixed-point problem

$$
w_{j}^{b}=\arg \max _{w_{j} \leq w_{m}^{s}} \Pi^{s}\left(w_{j}, w_{j}^{b}\right) \text { s.t. } \Pi_{d}^{s}\left(w_{j}, w_{j}^{b}\right) \geq \Pi_{d}^{s}\left(w_{m}^{s}, w_{m}^{s}\right) .
$$

The unique solution is $w_{j}^{b}=w_{m}^{s}$. It follows that there exists a monopoly-like equilibrium with beliefs consistent with forward induction if and only if $\Pi\left(w_{m}^{s}, 1\right) \leq \Pi\left(w_{m}^{s}, 0\right)$, which arises when the softening effect is strong enough. We have:

Proposition 7. Suppose $N=M+1$. Under secret offers, there exists $\delta_{m}^{s}>\delta_{m}$ such that after $M$ mergers, monopoly-like equilibria exist if and only if $\delta \geq \delta_{m}^{s}$. Moreover, $w_{m}^{s}<w_{m}$.

Proof. See our Online Appendix (Section I.1) on the Journal's editorial web site.

Thus, the monopoly-like equilibrium is both less harmful to consumers $\left(w_{m}^{s}<w_{m}\right.$, resulting in lower downstream prices) and harder to sustain $\left(\delta_{m}^{s}>\delta_{m}\right)$ when upstream offers are secret. The intuition for $w_{m}^{s}<w_{m}$ is that under public offers, when $U_{i}-D_{i}$ lowers its upstream price, the other firms understand that both $U_{i}-D_{i}$ and $D_{M+1}$ 


\section{ANTICOMPETITIVE VERTICAL MERGER WAVES}

will become more aggressive in the downstream market. By strategic complementarity, those firms decrease their downstream prices, hurting $U_{i}-D_{i}$. Under private contracting, the other firms do not observe the deviation, and so this adverse strategic effect is not present. ${ }^{32}$ The inequality $\delta_{m}^{s}>\delta_{m}$ follows as $w_{m}^{s}<w_{m}$, implying that the softening effect is weaker under secret offers. In light of this, it seems undesirable to force upstream firms to disclose the terms of their vertical contracts, as such a policy makes foreclosure both more likely and more harmful.

We close this subsection by showing that when $M=2$ and $N=4$, symmetric collusive-like equilibria continue to exist under secret offers, but under conditions that are more stringent than under public offers:

Proposition 8. Suppose $M=2$ and $N=4$. Under secret offers, there exists $\underline{\delta}_{c}^{s}>\underline{\delta}_{c}$ such that after $M$ mergers, symmetric collusive-like equilibria in passive beliefs exist if and only if $\underline{\delta}_{c}^{s} \leq \delta<\bar{\delta}_{c}$. For given $\delta$, the interval of input prices that can be sustained in such equilibria is a subset of the interval of prices that can be sustained under public offers.

Proof. See our Online Appendix (Section I.2) on the Journal's editorial web site.

\section{CONCLUSION}

The main message conveyed in the paper is that (waves of) vertical mergers that eliminate the last unintegrated upstream firm can give rise to partial foreclosure in the input market and worsen market performance. The optimal merger approval policy depends on whether the merger under consideration would result in an industry structure in which all upstream firms are vertically integrated. If not, then the merger should be cleared as the merger-induced synergies improve market performance. If instead the merger does eliminate the last unintegrated upstream firm, then the antitrust authority should trade off the benefits of merger-induced synergies against partial foreclosure effects. 


\section{J. HOMBERT, J. POUYET AND N. SCHUTZ}

We study the determinants of this tradeoff. We find that the optimal merger policy is not necessarily monotonic in the strength of synergies or in the degree of substitutability between final products. The intuition is that stronger synergies (resp., downstream

products being closer substitutes) make partial foreclosure easier to sustain, but also make such partial foreclosure less detrimental to market performance when it arises. In a sense, these results are bad news since the exact strength of synergies or the degree of downstream product differentiation may be hard to pinpoint for antitrust authorities. However, other determinants, which, arguably, may also be more readily observable to antitrust authorities, appear to have more clear-cut effects: Our results suggest that the last merger of the wave is more likely to be detrimental to market performance when there are few upstream firms or many downstream firms, and when upstream contracts are public, linear, and non-discriminatory.

Finally, we wish to highlight the minimal set of conditions under which partial foreclosure can arise after a merger wave. As our analysis reveals, all that is needed is that vertically integrated firms know their upstream market share when they set their downstream price. This condition is satisfied when upstream offers are public, because vertically integrated firms can anticipate downstream firms' supplier choices. It also holds when upstream contracts are secret and signed before downstream prices are set. It fails only when upstream offers are secret and upstream suppliers are chosen after downstream prices are set. This suggests that vertical merger waves are less likely to be harmful in industries in which input supply relationships can be adjusted faster than downstream prices.

\section{APPENDIX}

\section{Equilibrium of Stage 3: Formal Analysis}

Let $\hat{\gamma}=\gamma N / \mathcal{N}$. The first-order conditions (5) and (6) can be rewritten as

$$
0=1-p_{k}-\hat{\gamma}\left(p_{k}-\bar{p}\right)-\left(p_{k}-w\right)\left(1+\hat{\gamma} \frac{N-1}{N}\right)
$$




\section{ANTICOMPETITIVE VERTICAL MERGER WAVES}

$$
0=1-p_{i}-\hat{\gamma}\left(p_{i}-\bar{p}\right)-\left(p_{i}-m+\delta\right)\left(1+\hat{\gamma} \frac{N-1}{N}\right)+(w-m) \alpha_{i} \hat{\gamma} \frac{N-K}{N},
$$

where $\bar{p} \equiv\left(\sum_{j=1}^{N} p_{j}\right) / N$ is the average price. Adding up those first-order conditions, we obtain the equilibrium average price:

$$
\bar{P}^{K}(w, \bar{\alpha})=\frac{1+\left(1+\hat{\gamma} \frac{N-1}{N}\right)\left(\frac{N-K}{N} w+\frac{K}{N}(m-\delta)\right)+(w-m) \bar{\alpha} \hat{\gamma} \frac{K(N-K)}{N^{2}}}{2+\hat{\gamma} \frac{N-1}{N}} .
$$

The function $\bar{P}^{K}(\cdot)$ is strictly increasing in both of its arguments and depends on $\left(\alpha_{j}\right)_{1 \leq j \leq K}$ only through $\bar{\alpha}$.

Plugging $\bar{P}^{K}(w, \bar{\alpha})$ into equations (9) and (10) yields the equilibrium downstream prices:

$$
\begin{aligned}
P_{d}^{K}(w, \bar{\alpha}) & =\frac{1+\hat{\gamma} \bar{P}^{K}(w, \bar{\alpha})+\left(1+\hat{\gamma} \frac{N-1}{N}\right) w}{2+\hat{\gamma}+\hat{\gamma} \frac{N-1}{N}}, \\
P^{K}\left(w, \bar{\alpha}, \alpha_{i}\right) & =\frac{1+\hat{\gamma} \bar{P}^{K}(w, \bar{\alpha})+\left(1+\hat{\gamma} \frac{N-1}{N}\right)(m-\delta)+\alpha_{i} \hat{\gamma} \frac{N-K}{K}(w-m)}{2+\hat{\gamma}+\hat{\gamma} \frac{N-1}{N}} .
\end{aligned}
$$

The functions $P_{d}^{K}(\cdot)$ and $P^{K}(\cdot)$ are strictly increasing in all of their arguments, as stated in Lemma 1.

Moreover, equation (9) and the linear demand specification imply that the equilibrium output of an unintegrated downstream firm depends only on $w$ and $\bar{\alpha}$ :

$$
Q_{d}^{K}(w, \bar{\alpha})=\frac{1+\gamma}{\mathcal{N}+\gamma N}\left(1+\hat{\gamma} \frac{N-1}{N}\right)\left(P_{d}^{K}(w, \bar{\alpha})-w\right) .
$$

Similarly, using equation (10), we find that the equilibrium output of vertically integrated firm $U_{i}-D_{i}$ depends only on $w, \bar{\alpha}$, and $\alpha_{i}$ :

$$
Q^{K}\left(w, \bar{\alpha}, \alpha_{i}\right)=\frac{(1+\gamma)\left(\left(1+\hat{\gamma} \frac{N-1}{N}\right)\left(P^{K}\left(w, \bar{\alpha}, \alpha_{i}\right)-m+\delta\right)-\hat{\gamma} \frac{N-K}{N} \alpha_{i}(w-m)\right)}{\mathcal{N}+\gamma N} .
$$

This implies that those firms' equilibrium profits can be written as $\Pi_{d}^{K}(w, \bar{\alpha})$ and 


\section{J. HOMBERT, J. POUYET AND N. SCHUTZ}

$\Pi^{K}\left(w, \bar{\alpha}, \alpha_{i}\right)$, as stated in Section $\operatorname{III}(\mathrm{i})$.

Facts about equilibrium profit functions

Lemma 6. The following holds:

(i) The maximization problem $\max _{w \in[m, \bar{m}]} \Pi(w, 1)$ has a unique solution, $w_{m}>m$.

(ii) $\Pi(w, \alpha)$ is strictly concave in $\alpha$ for every $w>m$.

(iii) $\Pi(w, 0)$ is strictly increasing in $w$.

Proof. To prove part (i), recall that equilibrium downstream prices and quantities are linear in $w$. It follows that $\Pi(w, 1)$ is quadratic and hence continuous in $w$. The maximization problem therefore has a solution. Moreover, letting $U_{i}-D_{i}$ be the upstream supplier, we have:

$$
\Pi(w, 1)=\left(p_{i}-m+\delta\right) q_{i}(p)+(w-m) \sum_{k=M+1}^{N} q_{k}(p)
$$

where the price vector $p$ is set equal to its equilibrium value. Differentiating this expression with respect to $w$ at $w=m$ and using the envelope theorem yields:

$$
\left.\frac{\partial \Pi(w, 1)}{\partial w}\right|_{w=m}=\left(p_{i}-m+\delta\right) \sum_{j \neq i} \frac{d p_{j}}{d w} \frac{\partial q_{i}}{\partial p_{j}}
$$

where $d p_{j} / d w$ is equal to either $\partial P /\left.\partial w\right|_{(m, 1)}$ or $P_{d}^{\prime}(m)$, depending on whether $D_{j}$ is vertically integrated or not. As all those derivatives are positive by Lemma 1, it follows that $\partial \Pi /\left.\partial w\right|_{(m, 1)}>0$. Summing up, $\Pi(\cdot, 1)$ is quadratic and strictly increasing in the neighborhood of $m$. Hence, that function is either strictly increasing or inverse- $U$ shaped on $[m, \bar{m}]$. The maximization problem therefore has a unique solution, which is strictly greater than $m$. 


\section{ANTICOMPETITIVE VERTICAL MERGER WAVES}

To prove part (ii), recall that

$$
\Pi\left(w, \alpha_{i}\right)=\left(P\left(w, \alpha_{i}\right)-m+\delta\right) Q\left(w, \alpha_{i}\right)+(w-m) \alpha_{i}(N-M) Q_{d}(w) .
$$

As the second term in equation (13) is linear in $\alpha_{i}$, all we need to do is show that the first term is strictly concave in $\alpha_{i}$. Differentiating equation (12) with respect to $\alpha_{i}$, we find:

$$
\frac{\partial Q\left(w, \alpha_{i}\right)}{\partial \alpha_{i}}=\frac{1+\gamma}{\mathcal{N}+\gamma N} \hat{\gamma} \frac{N-M}{N}(w-m)\left(\frac{1+\hat{\gamma} \frac{N-1}{N}}{2+\hat{\gamma}+\hat{\gamma} \frac{N-1}{N}}-1\right)
$$

which is strictly negative. The first term in equation (13) is therefore the product of a term that is linear and strictly increasing in $\alpha_{i}$ (i.e., $P\left(w, \alpha_{i}\right)-m+\delta$ ) and a term that is linear and strictly decreasing in $\alpha_{i}$ (i.e., $\left.Q\left(w, \alpha_{i}\right)\right)$. It follows that $\Pi(w, \cdot)$ is strictly concave.

Part (iii) follows immediately from the fact that all equilibrium downstream prices are strictly increasing in $w$.

\section{REFERENCES}

Ahern, K. R. and Harford, J., 2014, 'The Importance of Industry Links in Merger Waves,' The Journal of Finance, 69(2), pp. 527-576.

Allain, M.L., Chambolle, C. and Rey, P., 2016, 'Vertical Integration as a Source of Hold-Up,' Review of Economic Studies, 83(1), pp. 1-25.

Athey, S. and Schmutzler, A., 2001, 'Investment and Market Dominance,' RAND Journal of Economics, 32(1), pp. 1-26.

Avenel, E., 2012, 'Upstream Capacity Constraint and the Preservation of Monopoly Power in Private Bilateral Contracting,' Journal of Industrial Economics, 60(4), pp. $578-598$.

Bonanno, G. and Vickers, J., 1988, 'Vertical Separation,' Journal of Industrial Economics, 36(3), pp. 257-265. 


\section{J. HOMBERT, J. POUYET AND N. SCHUTZ}

Bork, R. H., 1978, The Antitrust paradox: A Policy at War with Itself (New York: Basic Books)

Bourreau, M., Hombert, J., Pouyet, J. and Schutz, N., 2011, 'Upstream Competition between Vertically Integrated Firms,' Journal of Industrial Economics, 59(4), pp. 677713.

Chen, Y., 2001, 'On Vertical Mergers and their Competitive Effects,' RAND Journal of Economics, 32(4), pp. 667-685.

Chen, Y. and Riordan, M. H., 2007, 'Vertical Integration, Exclusive Dealing, and Ex Post Cartelization,' RAND Journal of Economics, 38(1), pp. 2-21.

Choi, J. P. and Yi, S.S., 2000, 'Vertical Foreclosure with the Choice of Input Specifications,' RAND Journal of Economics, 31(4), pp. 717-743.

Corts, K., 1998, 'Third-Degree Price Discrimination in Oligopoly: All-Out Competition and Strategic Commitment,' RAND Journal of Economics, 29(2), pp. 306-323.

DeGraba, P., 1990, 'Input Market Price Discrimination and the Choice of Technology,' American Economic Review, 80(5), pp. 1246-1253.

Fan, J. P. H. and Goyal, V. K., 2006, 'On the Patterns and Wealth Effects of Vertical Mergers,' The Journal of Business, 79(2), pp. 877-902.

Fudenberg, D. and Tirole, J., 1991, Game Theory (MIT Press, Cambridge, Massachussetts, U.S.A)

Gärtner, D. and Halbheer, D., 2009, 'Are There Waves in Merger Activity after All?' International Journal of Industrial Organization, 27(6), pp. 708-718.

Hart, O. and Tirole, J., 1990, 'Vertical Integration and Market Foreclosure,' Brookings Papers on Economic Activity, pp. 205-276.

Hombert, J., Pouyet, J. and Schutz, N., 2013, Anticompetitive Vertical Merger Waves (Discussion Paper Series of SFB/TR 15 Governance and the Efficiency of Economic Systems 440) 


\section{ANTICOMPETITIVE VERTICAL MERGER WAVES}

Inderst, R. and Shaffer, G., 2009, 'Market Power, Price Discrimination, and Allocative Efficiency in Intermediate-Goods Market,' RAND Journal of Economics, 40(4), pp. $658-672$.

Inderst, R. and Valletti, T., 2009, 'Price Discrimination in Input Market,' RAND Journal of Economics, 40(1), pp. 1-19.

Inderst, R. and Valletti, T., 2011, 'Incentives for Input Foreclosure,' European Economic Review, 55(6), pp. 820-831.

Katz, M., 1987, 'The Welfare Effect of Third-Degree Price Discrimination in Intermediate Good Markets,' American Economic Review, 77(1), pp. 154-167.

Loertscher, S. and Reisinger, M., 2014, 'Market structure and the competitive effects of vertical integration,' RAND Journal of Economics, 45(3), pp. 471-494.

McAfee, R. P. and Schwartz, M., 1994, 'Opportunism in Multilateral Vertical Contracting: Nondiscrimination, Exclusivity, and Uniformity,' American Economic Review, 84(1), pp. 210-230.

McLaren, J., 2000, “Globalization” and Vertical Structure,' American Economic Review, 90(5), pp. 1239-1254.

Mitchell, M. L. and Mulherin, J. H., 1996, 'The Impact of Industry Shocks on Takeover and Restructuring Activity,' Journal of Financial Economics, 41(2), pp. 193-229.

Nocke, V. and White, L., 2007, 'Do Vertical Mergers Facilitate Upstream Collusion?' American Economic Review, 97(4), pp. 1321-1339.

Normann, H.T., 2009, 'Vertical Mergers, Raising Rivals' Costs and Upstream Collusion,' European Economic Review, 53(4), pp. 461-480.

Ordover, J., Saloner, G. and Salop, S., 1990, 'Equilibrium Vertical Foreclosure,' American Economic Review, 80(1), pp. 127-142.

Posner, R., 1976, Antitrust law: An Economic Perspective (University of Chicago Press) Reiffen, D., 1992, 'Equilibrium Vertical Foreclosure: Comment,' American Economic 


\section{J. HOMBERT, J. POUYET AND N. SCHUTZ}

Review, 82(3), pp. 694-97.

Reisinger, M. and Tarantino, E., 2015, 'Vertical Integration, Foreclosure, and Productive Efficiency,' RAND Journal of Economics, 46(3), pp. 461-479.

Rey, P. and Tirole, J., 2007, 'A Primer on Foreclosure,' in Armstrong, M. and Porter, R. (eds.), Handbook of Industrial Organization, Vol. III (North Holland).

Rey, P. and Vergé, T., 2004, 'Bilateral Control with Vertical Contracts,' RAND Journal of Economics, 35(4), pp. 728-746.

Riordan, M. H., 2008, 'Competitive Effects of Vertical Integration,' in Buccirossi, P. (eds.), Handbook of Antitrust Economics (MIT Press)

Salinger, M., 1988, 'Vertical mergers and market foreclosure,' Quarterly Journal of Economics, 103(2), pp. 345-356.

Salinger, M., 1991, 'Vertical Mergers in Multi-Product Industries and Edgeworth's Paradox of Taxation,' Journal of Industrial Economics, 39(5), pp. 545-556.

Schutz, N., 2013, Competition with Exclusive Contracts in Vertically Related Markets: An Equilibrium Non-Existence Result (Discussion Paper Series of SFB/TR 15 Governance and the Efficiency of Economic Systems 439)

Shenoy, J., 2012, "An Examination of the Efficiency, Foreclosure, and Collusion Rationales for Vertical Takeovers,' Management Science, 58(8), pp. 1482-1501.

Shubik, M. and Levitan, R., 1980, Market Structure and Behavior (Harvard University Press)

Vives, X., 1999, Oligopoly pricing: Old ideas and new tools (MIT Press, Cambridge, Massachussetts, U.S.A.)

Yoshida, Y., 2000, 'Third-Degree Price Discrimination in Input Markets: Output and Welfare,' American Economic Review, 90(1), pp. 240-246. 


\section{ANTICOMPETITIVE VERTICAL MERGER WAVES}

\section{Notes}

${ }^{1}$ Waves of vertical (dis-)integration have received some attention in the international trade literature in the context of the rise of outsourcing (McLaren [2000]).

${ }^{2}$ See, e.g., paragraph 102 in EC COMP/M.2389 Shell/DEA. See also EC COMP/M.2533 BP/E.ON.

${ }^{3}$ The Premdor/Masonite merger documented in Riordan [2008] is another example of a vertical merger which eliminates the last unintegrated upstream producer. In the satellite navigation industry in 2007, when TomTom and Nokia announced their planned acquisitions of producers of navigable digital map databases (the upstream good) Tele Atlas and Navteq, the European Commission's main concern was that the upstream market would end up being supplied by two vertically integrated firms (see EC COMP/M.4854 TomTom/Tele Atlas and COMP/M.4942 Nokia/Navteq).

${ }^{4}$ Throughout the paper, statements such as " $\mathrm{X}$ is more likely to arise" should be understood as "X arises for a larger set of parameter values."

${ }^{5}$ Other contributions include Salinger [1988] who considers Cournot competition in both markets, Salinger [1991] who studies a setting with a downstream monopoly and an upstream duopoly, and the strand of literature initiated by Hart and Tirole [1990] and surveyed by Rey and Tirole [2007], which analyzes the consequences of upstream secret offers, focusing mainly on the commitment problem faced by an upstream monopolist. See Avenel [2012] and Reisinger and Tarantino [2015] for recent contributions.

${ }^{6}$ As explained at the end of Section III(ii)(b), collusive-like equilibria are much better behaved than the matching-like equilibria characterized by Bourreau et al. [2011]. In particular, the latter are always unstable and Pareto-dominated, whereas the former can be both stable and Pareto-efficient.

${ }^{7}$ The alternative source can come from a competitive fringe of less efficient upstream firms.

${ }^{8}$ Synergies could alternatively be modeled by assuming that the upstream cost decreases while the downstream transformation cost remains constant, as in, e.g., Chen [2001]. Our approach is more tractable as it ensures that all upstream firms have the same cost, regardless of whether they are 


\section{J. HOMBERT, J. POUYET AND N. SCHUTZ}

vertically integrated.

${ }^{9}$ See our earlier working paper (Hombert, Pouyet, and Schutz [2013]) for results without linear demand.

${ }^{10}$ Allowing $\mathcal{N}$ to differ from $N$ will later allow us to perform comparative statics on the number of downstream firms without arbitrarily changing the underlying preferences.

${ }^{11}$ Firms cannot merge horizontally and a downstream firm can acquire at most one upstream firm.

${ }^{12}$ Nocke and White [2007] use a similar device to convexify the set of feasible market shares.

${ }^{13}$ Vertically integrated firms are not allowed to buy the input in the upstream market. It is easy to show that they would have no incentive to do so.

${ }^{14}$ The assumption of simultaneous pricing and supplier choice decisions simplifies the analysis by ensuring that downstream firms buy the input at the lowest price available. We show in Section F of our Online Appendix, available on the Journal's editorial web site, that our results continue to go through if downstream firms choose their supplier before downstream prices are set.

${ }^{15}$ In the zero-merger subgame, the deviation is that any unintegrated upstream firm that does not already have an upstream market share of 1 would rather undercut.

${ }^{16}$ This follows by our selection criterion if $w=\bar{m}$ and by sequential rationality if $w<\bar{m}$.

${ }^{17}$ The assumption that only $U_{j}-D_{j}$ 's market share is affected is made to fix ideas and simplify the exposition. Recall from Section III(i) that $U_{i}-D_{i}$ 's equilibrium profit depends only on $w$ and $\alpha_{i}$.

${ }^{18}$ From now on, we assume that $\delta$ is not too high so that the unconstrained maximization problem $\max _{w} \Pi(w, 1)$ has an interior solution, and that $\bar{m}$ is high enough so that it does not constrain $w_{m}$.

${ }^{19}$ Those thresholds are functions of the parameters. It can be shown that $\underline{\delta}_{c}=0$ if and only if $M=2$ and $\gamma$ is high, whereas $\delta_{m}=0$ if and only if $M=2, N=3$, and $\gamma$ is high. For details, see our Online Appendix (Section B) on the Journal's editorial web site.

${ }^{20}$ The reason why collusive-like equilibria do not arise in BHPS is that there is only one unintegrated downstream firm which does not randomize its supplier choice by assumption, so that upstream market shares can only be 0 or 1 . BHPS also consider an extension with more than one unintegrated 


\section{ANTICOMPETITIVE VERTICAL MERGER WAVES}

downstream firm (see their section $\mathrm{V}(\mathrm{i})(\mathrm{b})$ ), but still restrict market shares to be 0 or 1 . BHPS briefly address the possibility that vertically integrated firms share the upstream market at a common price (see their section $\mathrm{V}(\mathrm{i})(\mathrm{d})$ ), but assume an exogenously-given, symmetric tie-breaking rule. By contrast, the tie-breaking rule is determined in equilibrium in the present paper.

${ }^{21}$ For details, see our Online Appendix (Section C) on the Journal's editorial web site.

${ }^{22}$ In addition to the complementarity induced by the foreclosure effect, synergies may introduce some substitutability. This kind of substitutability arises if a firm is less willing to pay for a marginal cost reduction when its rivals already have a low marginal cost, as in Athey and Schmutzler [2001].

${ }^{23}$ The result that all downstream firms' owners suffer from the wave continues to obtain under other bargaining protocols. For example, if we allow instead the upstream firms to bid to acquire the downstream firms, then it is possible to show that the equilibrium payoffs are the same as when downstream firms bid.

${ }^{24}$ We refrain from introducing the antitrust authority as a player in the merger game to ease exposition. The reader can think of the authority as being called upon every time a merger is proposed in stage 1 , and deciding whether to approve it. The analysis in this section describes the equilibrium behavior in this game.

${ }^{25}$ Figures $1-3$ were constructed by setting $\mathcal{N}=5$ and $m=0.25$. Those specific values involve no loss of generality as they simply rescale $\gamma$ and $\delta$. For details, see our Online Appendix (Section A) on the Journal's editorial web site.

${ }^{26}$ The fact that monopoly-like equilibria exist if and only if $\gamma$ is sufficiently high was already pointed out by Bourreau et al. [2011] in the case where $M=2, N=3$, and $\delta=0$.

${ }^{27}$ The Commission's reasoning is challenged by Inderst and Valletti [2011], who argue that low downstream margins are indicative of closely substitutable final products, and thus strong incentives to raise rivals' costs.

${ }^{28}$ Loertscher and Reisinger [2014] derive a similar policy recommendation, albeit for very different reasons, in a setup where downstream firms have market power in both the upstream and the 


\section{J. HOMBERT, J. POUYET AND N. SCHUTZ}

downstream market.

${ }^{29}$ If upstream offers are non-exclusive, i.e., if a downstream firm can accept multiple offers, then negative fixed fees cannot arise in equilibrium (see Chen [2001]). If instead upstream offers are exclusive and negative fixed fees are allowed, then the no-merger subgame does not have an equilibrium (Schutz [2013]).

${ }^{30}$ Passive beliefs have been criticized on two grounds. First, such beliefs sometimes appear unreasonable. For example, in differentiated-goods Bertrand settings, an upstream firm that deviates on one of its contracts would find it profitable to deviate on its other contracts as well, and so passive beliefs are inconsistent with the upstream firm's incentives (Rey and Vergé [2004]). In Cournot settings, such beliefs are unreasonable if upstream firms face capacity constraints (Avenel [2012]). Second, equilibria in passive beliefs fail to exist in some settings (see again Rey and Vergé [2004]). In our framework, the equilibrium non-existence problem does not arise. Moreover, starting from an equilibrium candidate in which the input is priced at marginal cost, passive beliefs imply that a downstream firm would always accept a downward deviation and never accept an upward deviation, which does not strike us as unappealing.

${ }^{31}$ See Fudenberg and Tirole [1991] for a textbook treatment of forward induction. McAfee and Schwartz [1994] and Rey and Vergé [2004] use forward induction to motivate the concept of wary beliefs in a vertical relations model with an upstream bottleneck.

${ }^{32}$ This effect is reminiscent of the opportunism problem identified by Hart and Tirole [1990]. 

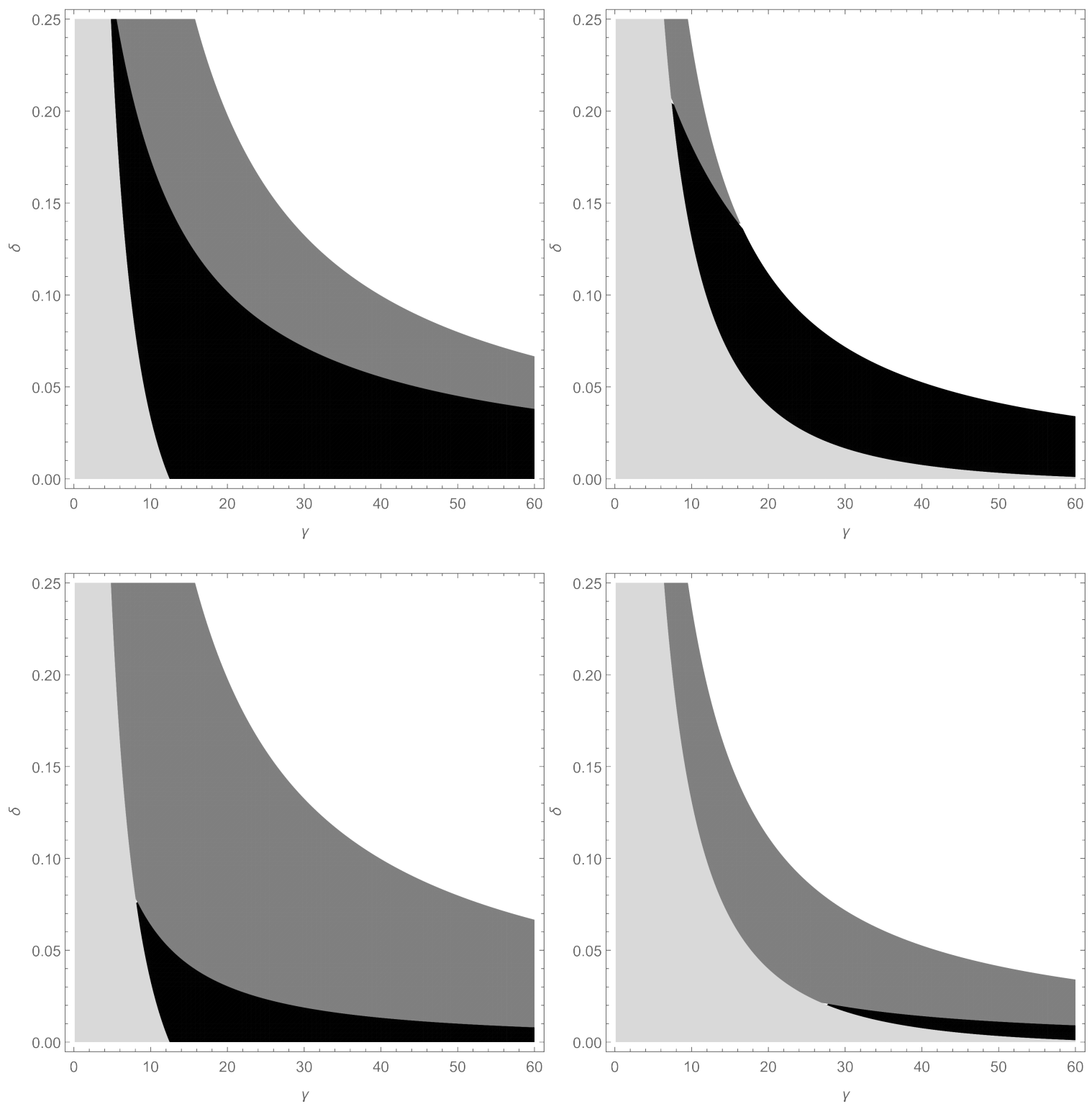

Figure 1

Welfare effect of the last merger with $M=2$ and $N=3$

Notes. Top panels: $\lambda=0$. Bottom panels: $\lambda=1$. Left panels: selection criterion $(\mathcal{C})$. Right panels: selection criterion $(\mathcal{M})$.

In the black-shaded area, the second merger gives rise to partial foreclosure and worsens market performance. In the dark-gray-shaded area, it gives rise to partial foreclosure but improves market performance. In the light-gray-shaded area, the Bertrand outcome arises post-merger. In the unshaded area, $\delta$ is so high that the monopoly upstream price is no longer interior (right panels) or that collusivelike equilibria do not exist (left panels); those cases are ruled out by assumption. 

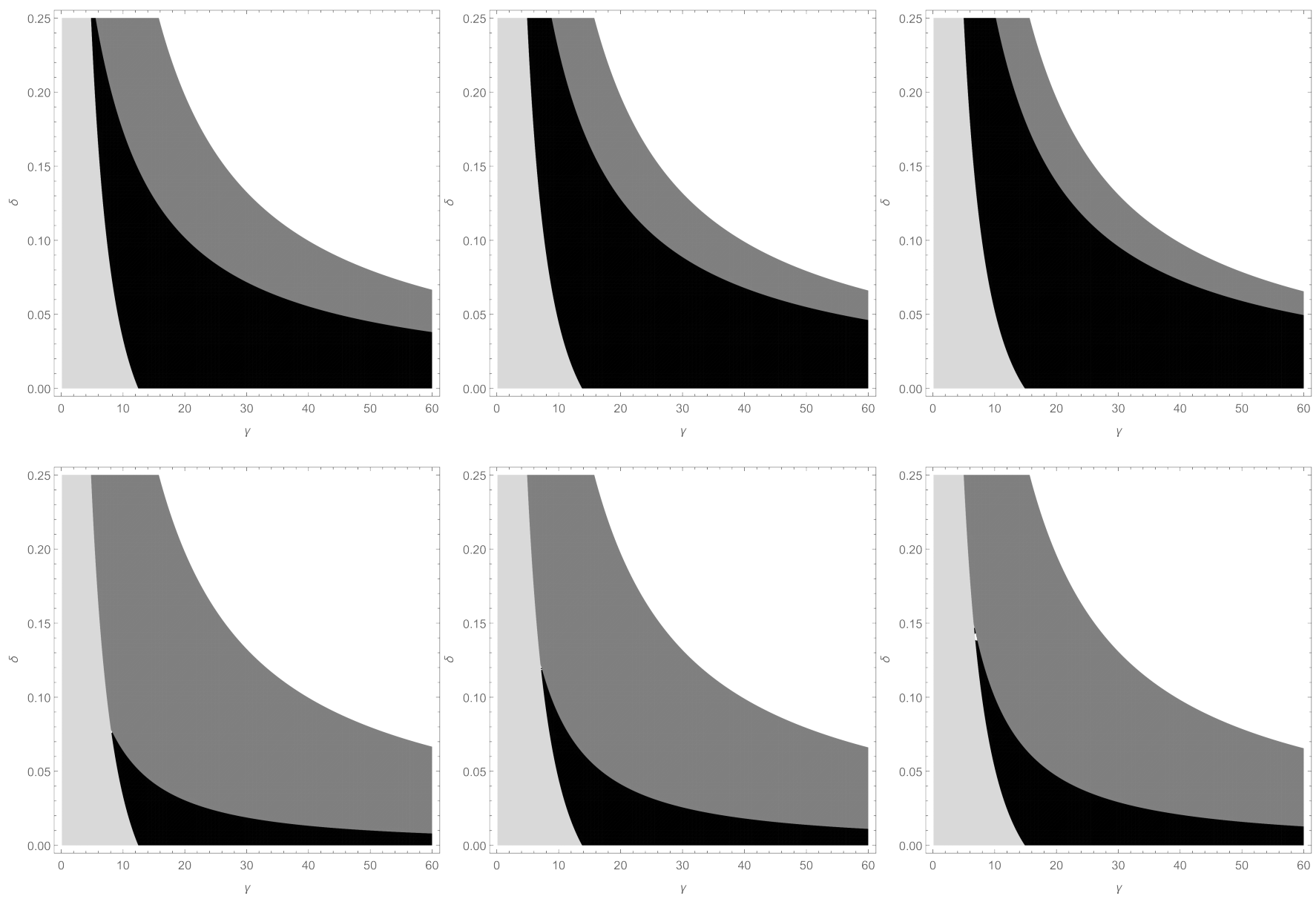

Figure 2

Welfare effect of the last merger with $M=2$ and $N=3,4,5$

Notes. Top panels: $\lambda=0$. Bottom panels: $\lambda=1$. Left, middle, and right panels: $N=3$, 4 , and 5 , respectively. In all panels, selection criterion $(\mathcal{C})$ is assumed. The color code is the same as in Figure 1. 

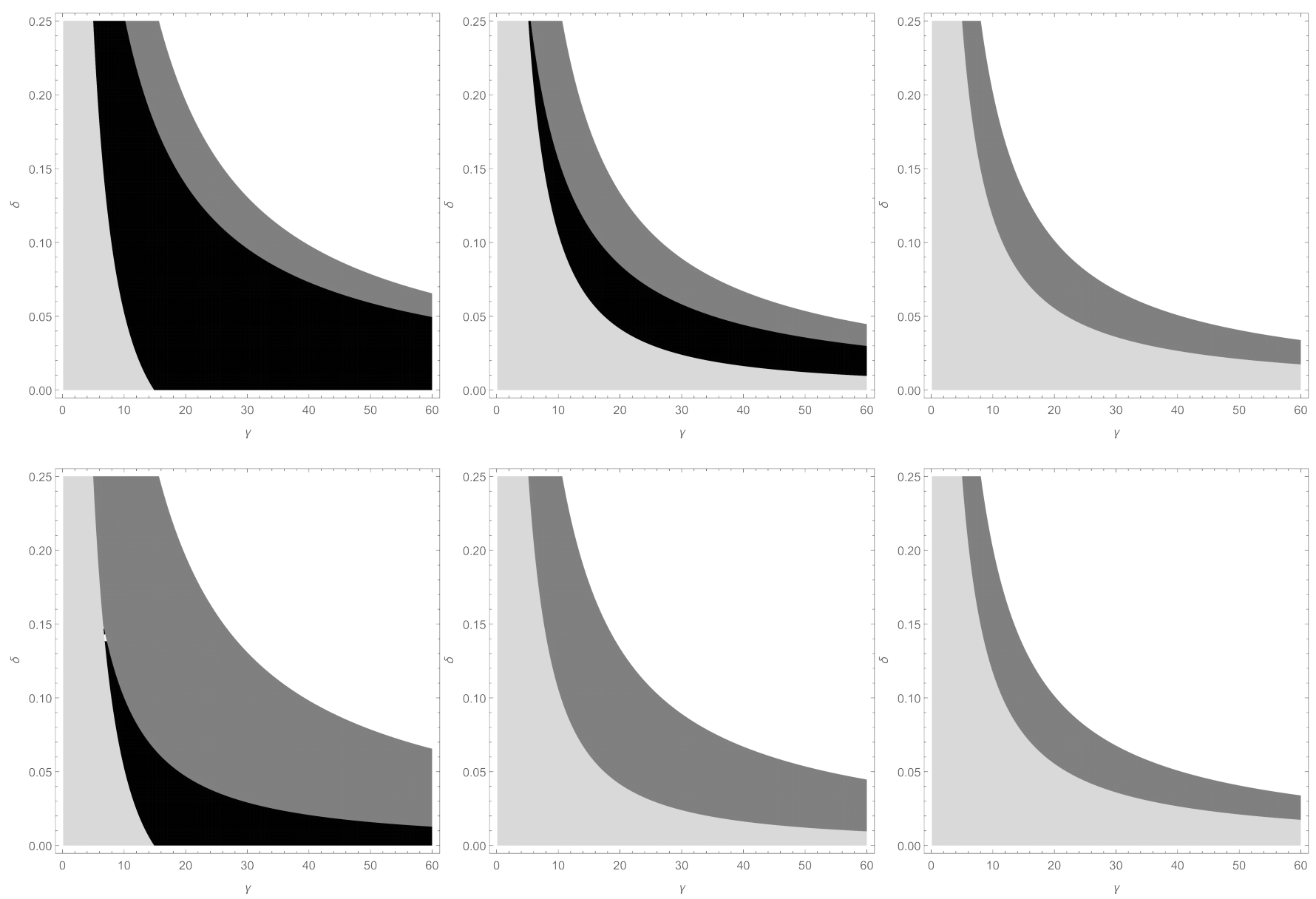

Figure 3

Welfare effect of the last merger with $N=5$ and $M=2,3,4$

Notes. Top panels: $\lambda=0$. Bottom panels: $\lambda=1$. Left, middle, and right panels: $M=2,3$, and 4 , respectively. In all panels, selection criterion $(\mathcal{C})$ is assumed. The color code is the same as in Figure 1. 